\title{
A cross-sectional survey of patient satisfaction and subjective experiences of treatment with fingolimod
}

This article was published in the following Dove Press journal:

Patient Preference and Adherence

15 April 2013

Number of times this article has been viewed

\section{Kristin A Hanson' \\ Neetu Agashivala ${ }^{2}$ \\ Sonja M Stringer ${ }^{3}$ \\ Zaneta Balantac ${ }^{3}$ \\ David W Brandes ${ }^{4}$}

'United BioSource Corporation, Dorval, QC, Canada; ${ }^{2}$ Novartis Pharmaceuticals Corporation, East Hanover, NJ, USA; ${ }^{3}$ United BioSource Corporation, Bethesda, MD, USA;

${ }^{4}$ Hope MS Center, Knoxville, TN, USA
Correspondence: Kristy Hanson Peri- and Post-Approval Services, United BioSource Corporation, I85 Dorval Avenue, Suite 500, Dorval, QC H9S 5J9, Canada

$\mathrm{Tel}+\mathrm{I} 5|4422827|$

Fax + I 5144228272

Email kristy.hanson@unitedbiosource.com
Background: Fingolimod is the first oral disease-modifying therapy indicated for the treatment of patients with relapsing forms of multiple sclerosis (MS) to reduce the frequency of clinical relapses and delay the progression of physical disability caused by MS.

Objective: To obtain data from MS patients who have taken fingolimod regarding their treatment choice, first-dose observation (FDO) experience, and treatment satisfaction.

Methods: Patients $\geq 18$ years old with physician-diagnosed MS in the United States who had taken at least one dose of fingolimod for the treatment of MS were invited to complete a web-based survey, which captured information on the reasons for starting fingolimod, FDO experience, and treatment satisfaction as measured by the Treatment Satisfaction Questionnaire for Medication (TSQM). A high TSQM scale score denotes high satisfaction.

Results: Survey respondents $(\mathrm{n}=380 ; 55 \%$ female) had a mean (standard deviation) age of 39.8 (12.6) years, and a mean (standard deviation) duration of MS of 9.8 (10.3) years. Overall, more than $80 \%$ of patients reported the first dose was moderately/very/extremely manageable, convenient, and easy to take. Although $80 \%$ of patients reported experiencing a side effect with the first dose, most were highly tolerable and only eleven patients (2.9\%) reported they were "Not at all" satisfied with the FDO experience. TSQM scale scores were highest for the side effect (79.4), followed by convenience (71.7), effectiveness (70.1), and global satisfaction (68.9) domains; relatively higher scores were observed among treatment-experienced patients. Both treatment-naïve and treatment-experienced patients indicated physician recommendation as the primary reason for starting fingolimod. Among treatment-experienced respondents $(n=273)$, $58 \%$ reported that their first choice for MS treatment would be fingolimod if selecting today.

Conclusion: Most fingolimod patients were satisfied with their FDO experience. Satisfaction with fingolimod was high and observed higher among treatment-experienced compared to treatment-naïve patients. Additional research is needed to understand key clinical and medication attributes underlying treatment satisfaction with fingolimod and other disease-modifying therapies.

Keywords: multiple sclerosis, patient survey, fingolimod, satisfaction, first dose

\section{Introduction}

Multiple sclerosis (MS) is a chronic inflammatory disorder of the central nervous system that is thought to be immune-mediated in nature. ${ }^{1}$ Approximately 400,000 people in the United States and 2.1 million worldwide are affected by MS. ${ }^{2}$ Relapsingremitting MS (RRMS), characterized by clearly defined attacks of worsening neurologic function and partial or complete recovery periods, is the most common type of MS and affects approximately $85 \%$ of MS patients. ${ }^{2}$ 
Since there is no cure for MS, the goals of current therapy include slowing disability progression, decreasing relapse rate, reducing accumulations of lesions in the brain, managing symptoms, and maintaining or improving health-related quality of life. The National Multiple Sclerosis Society recommends patients consider treatment with a diseasemodifying therapy (DMT) as soon as possible following a definite diagnosis of MS with active, relapsing disease. ${ }^{2}$ Currently, nine DMTs have demonstrated efficacy in reducing the rate and severity of MS relapses and are approved by the US Food and Drug Administration (FDA) for use in patients with relapsing forms of MS.

Despite satisfactory efficacy, a recent systematic review showed high DMT discontinuation rates of $17 \%$ to $36 \%$ for injectable DMTs. ${ }^{3}$ Main reasons for discontinuing were adverse events and lack of treatment efficacy. In addition, psychological factors associated with regular injections, such as anxiety and injection phobia, and injection site reactions that may adversely impact medication adherence were commonly observed in both randomized controlled trials and observational studies. ${ }^{3}$

Fingolimod is the first FDA-approved oral MS treatment. Fingolimod given once daily has demonstrated superior efficacy to placebo and intramuscular interferon beta-1a in two pivotal clinical trials. In the Efficacy and Safety of Fingolimod in Patients with Relapsing-Remitting Multiple Sclerosis (FREEDOMS) study, the annualized relapse rate was significantly lower in patients treated with fingoli$\bmod (0.18$ for $0.5 \mathrm{mg} /$ day) compared with placebo $(0.40$; $P<0.001){ }^{4}$ In the Efficacy and Safety of Fingolimod in Patients with Relapsing-Remitting Multiple Sclerosis with Optional Extension Phase (TRANSFORMS) trial, the annual relapse rate was significantly lower in fingolimod users ( 0.20 for $1.25 \mathrm{mg}$ /day and 0.16 for $0.5 \mathrm{mg}$ /day) compared to interferon beta-1a $(0.33 ; P<0.001) .{ }^{5}$ In addition, indirect treatment comparisons have shown significantly reduced relapse incidence in RRMS patients on fingolimod compared to other first-line DMTs. ${ }^{6}$

Fingolimod has shown higher levels of adherence and persistence compared to the self-injectable DMTs. A recent analysis of administrative claims from a large pharmacy benefits management company in the US showed that patients initiating fingolimod demonstrated higher levels of both adherence and persistence, as measured by medication possession ratio $\geq 0.8$, proportion of days covered $\geq 0.8$, and time to discontinuation, compared to patients initiating one of the first-line self-injectable DMTs (interferon beta- $1 \mathrm{~b}$, interferon beta-1a, or glatiramer acetate) ${ }^{7,8}$ Patients may find it easier to adhere to oral treatments with fewer side effects than injectable DMTs associated with flu-like symptoms and injection site reactions. Both flu-like symptoms and injection site reactions were among the top reasons for discontinuing treatment with interferon beta in previous studies. ${ }^{9,10}$

While fingolimod has generally been safe in patients without pre-existing cardiovascular conditions, in both of the pivotal trials, fingolimod was associated with decreases in heart rate (HR) and atrioventricular conduction delays following administration of the initial dose. In a pooled analysis of the FREEDOMS and TRANSFORMS safety populations, fingolimod $0.5 \mathrm{mg} /$ day and $1.25 \mathrm{mg}$ /day resulted in mean HR decreases of $8 \mathrm{bpm}$ and $11 \mathrm{bpm}$, respectively, at nadir. ${ }^{11}$ This decrease occurred primarily within the first 6 hours and was transient, with HR returning to baseline levels within 1 month of treatment. ${ }^{12}$ Thus, the original package insert for fingolimod recommended that all patients be observed for the signs and symptoms of bradycardia for at least 6 hours after the first dose with hourly pulse and blood pressure measurements. ${ }^{11}$

Fingolimod became only recently available to MS patients in 2010, and there is very scarce data in the current medical literature describing real-world patient treatment experience. The present survey was designed to collect data on characteristics of patients initiating fingolimod treatment and to evaluate their first-dose observation (FDO) experience and treatment satisfaction.

\section{Methods}

\section{Study design}

This was a cross-sectional study to understand patient experience and satisfaction with fingolimod. The study protocol was approved by a central Institutional Review Board (E\&I Review Services, Corte Madera, CA, USA). Study participants anonymously answered a web-based survey that was fielded in the US between April 2012 and July 2012.

\section{Participants}

All study participants met the following eligibility criteria: $\geq 18$ years of age; living in the United States at the time of survey completion; able to read English; had a self-reported physician-based diagnosis of MS; and had used fingolimod as treatment for MS. In addition, all participants were required to provide informed consent before completing the survey. In order to obtain an adequate sample size and given that fingolimod had been on the market for less than 2 years at the time of the survey, the date of fingolimod initiation was not included as a part of the study inclusion/exclusion criteria. 
Study participants were recruited from either (1) a market research panel consisting of MS patients, or (2) clinical sites (Cullman, AL, USA; Tulsa, OK, USA; Franklin, TN, USA). All patients with an MS diagnosis in the market research panel were contacted for potential participation, whereas medical records were reviewed at the clinical sites, and only patients with a history of fingolimod use were contacted by the clinical sites.

Potential participants were sent either an email or postal introductory letter that described the purpose of the survey and provided a direct link and/or instructions on how to access the web-based survey. Upon entering the website, potential participants provided informed consent to participate in the survey and answered screening questions; eligible patients were allowed to proceed to and complete the survey. Remuneration was offered to respondents who completed the survey in the amount of a $\$ 10$ check.

\section{Measures}

\section{Survey development}

The web-based survey was designed specifically for this study to capture information about treatment choice and treatment experience of patients who have taken fingolimod for MS. The survey was developed based on the results of a targeted literature review and consultation with an MS clinical expert (DWB).

\section{Survey content}

The survey included questions on first-dose experience with fingolimod (see Table S1), reasons for starting and stopping fingolimod, treatment satisfaction, use of other DMTs, and respondent sociodemographic and clinical characteristics. First-dose experience was evaluated for all survey respondents, whereas treatment satisfaction was measured among self-reported current fingolimod users only. Figure 1 presents

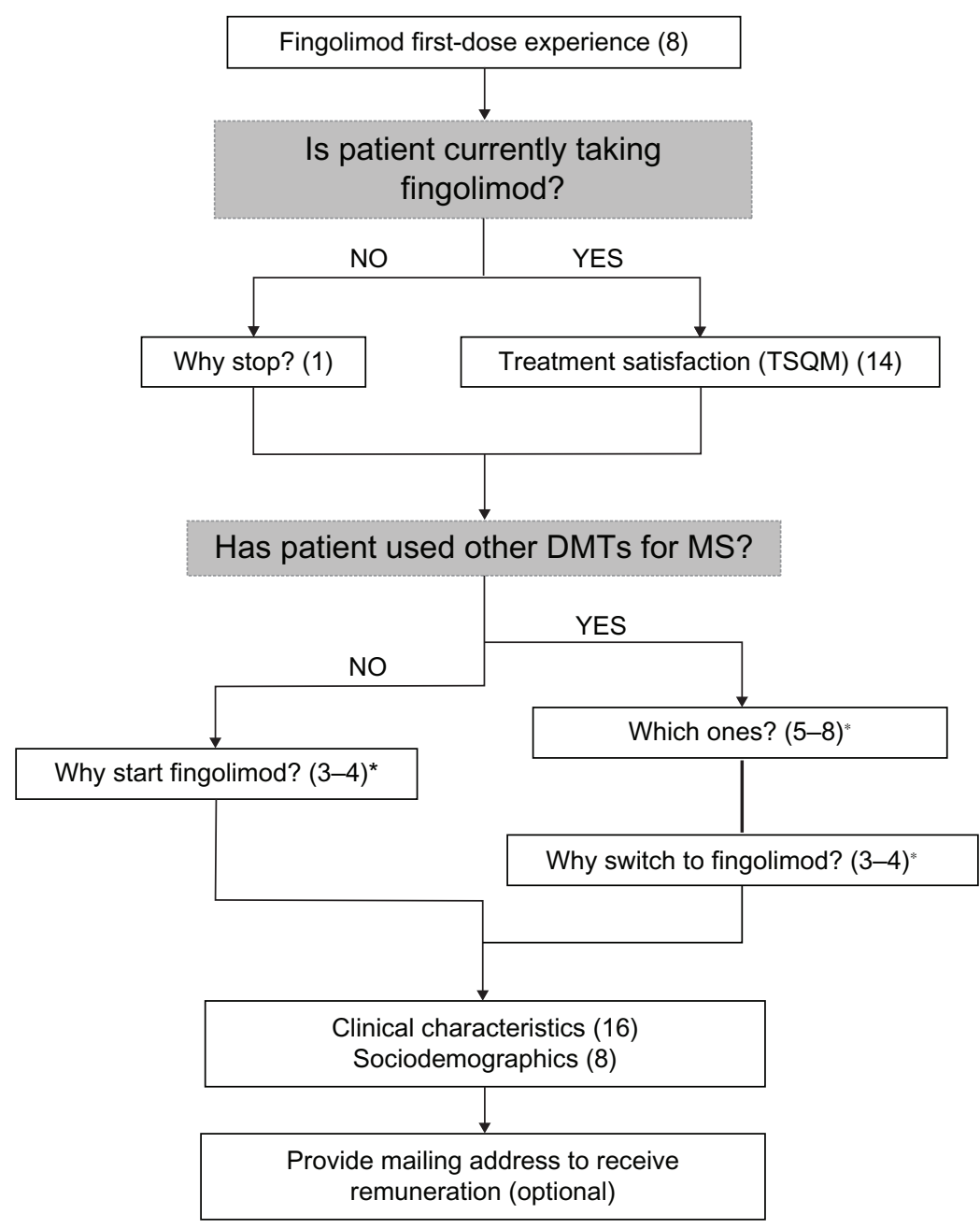

Figure I Fingolimod first-dose observation experience and treatment satisfaction survey flow diagram.

Note: (n) denotes the number of questions asked in each section of the survey; *number of questions asked depended on patient response to a leading question. Abbreviations: TSQM, Treatment Satisfaction Questionnaire for Medication; DMT, disease-modifying therapy; MS, multiple sclerosis; n, number. 
a summary of the survey questions asked of each respondent type (eg, current/prior fingolimod user; treatment-naïve/ treatment-experienced).

Respondent disease severity was evaluated using the Patient Determined Disease Steps (PDDS) instrument. The PDDS is a one-item instrument developed as an inexpensive surrogate for the Expanded Disability Status scale (EDSS) to evaluate disease progression in MS. ${ }^{13,14}$ With the PDDS, patients report their current level of disability on a descriptive nine-point scale ranging from normal (0) to bedridden (8). The PDDS is validated against the EDSS, and PDDS scores have been shown to be linearly and strongly correlated to the physician-administered EDSS $(r=0.93) .{ }^{14-17}$

The Treatment Satisfaction Questionnaire for Medication (TSQM) was used to assess treatment satisfaction with fingolimod among respondents taking the drug at the time of the survey. The TSQM is a 14-item instrument designed to measure satisfaction with a medication being taken in the setting of a clinical trial. The domains measured by the TSQM include side effects, effectiveness, convenience, and global satisfaction. Scores range from 0 to 100 for each of the four domains, with higher scores denoting greater satisfaction with treatment. ${ }^{18}$

\section{Statistical analyses}

Descriptive statistics were reported for all variables. Means, medians, standard deviations, and ranges were calculated for continuous variables; frequencies or proportions were computed for categorical variables. Exploratory analysis was conducted to determine whether treatment satisfaction differed among patients with or without prior DMT experience.

Student's $t$-tests were used for two-way comparisons of continuous variables and chi-square tests were used for categorical variables. Statistical significance was set at 0.05. SAS $^{\circledR}$ statistical software version 9.1.3 (SAS Institute Inc, Cary, NC, USA) was used to perform all analyses.

\section{Results}

A total of 5671 potential respondents entered the survey website; 3646 provided informed consent, 420 unique responders met study inclusion criteria, and 380 respondents completed the survey (response rate: $90.5 \%$; Figure 2). The primary reason for study exclusion was never having taken fingolimod $(n=2980)$.

A total of 310 reported they were current fingolimod users. Among those, 87 (28.1\%) were treatment-naïve and 223 $(71.9 \%)$ were treatment-experienced. Treatment-experienced

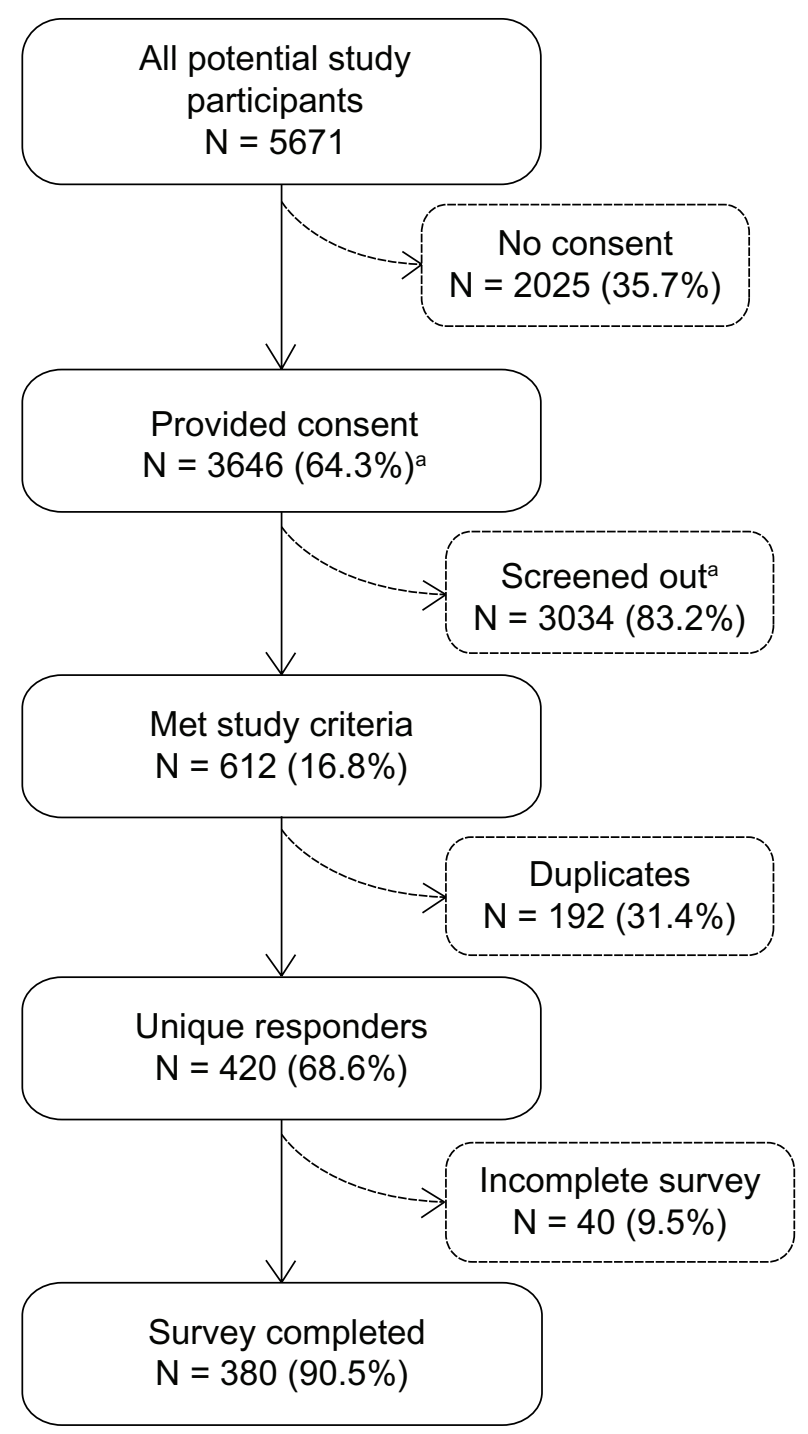

Figure 2 Study accrual and attrition.

Note: Percentages represent the number of patients meeting a specific criterion among all patients in the prior level (eg, patients not providing consent: 2025/5,617 = 35.7\%; patients providing consent: 3646/567I = 64.3\%). ${ }^{\text {aReasons for }}$ screen-out include: $<18$ years old $(N=24)$; not living in the United States $(N=10)$; not English-speaking $(N=9)$; no physician-diagnosed MS $(N=1650)$; never taken fingolimod $(\mathrm{N}=2980)$. Reasons are not mutually exclusive.

Abbreviations: $\mathrm{N}$, number; $\mathrm{MS}$, multiple sclerosis.

users most commonly switched from interferon beta- $1 \mathrm{~b}$ $(19.5 \%)$ or glatiramer acetate $(19.2 \%)$ to fingolimod. Mean (standard deviation) time since starting fingolimod was 11.4 (7.6) months in current users.

\section{Sociodemographic and clinical characteristics}

Overall, mean (standard deviation) respondent age was 39.8 (12.6) years, and 55\% were female. Mean disease duration, defined as time since MS diagnosis, was 9.8 (10.3) years. The most commonly diagnosed type of MS was RRMS 
(52\%), followed by secondary progressive MS (19\%) and clinically isolated syndrome (18\%). Approximately 40\% of respondents reported moderate-to-severe impairment as measured by the PDDS (score $\geq 3$ ) (Table 1).

Among current fingolimod users, treatment-naïve patients were significantly younger (mean age 33.3 versus 41.0 years; $P<0.0001)$, less likely to be female $(39.1 \%$ versus $57.8 \% ; P<0.01$ ), and demonstrated less severe MS disability/progression, as demonstrated by MS diagnosis type (eg, clinically isolated syndrome versus secondary progressive MS), employment status (full-time employed versus disabled), time since first MS symptom, time since MS diagnosis, number of lifetime MS relapses, and PDDS score, compared to treatment-experienced patients. Characteristics that were not significantly different between treatment-naïve and treatment-experienced groups included ethnicity, race, number of relapses in the past 6 months, and time since last MS relapse.

\section{Treatment selection}

Table 2 summarizes respondents' reasons for starting fingolimod. In respondents with no prior DMT use, the most reported primary reason for starting fingolimod was physician recommendation (32.7\%). Other important reasons included expectation of fewer side effects (13.5\%), ability to take medication at home $(13.5 \%)$, and expected efficacy of fingolimod (13.0\%).

Reasons for switching to fingolimod were similar to those for starting. Physician recommendation was the most common reason for switching, but there were relatively fewer patients reporting this $(15.6 \%)$ than among patients with no prior DMT use. Approximately one-third of respondents $(34.1 \%)$ reported that it was their idea to switch medications. In comparison, only $19.6 \%$ of treatment-naïve patients reported that starting fingolimod was their idea. Among patients with prior DMT use, side effects with previous treatment $(12.5 \%)$ and treatment failure with prior medication (11.0\%) were also frequently cited reasons for switching.

\section{First-dose experience}

Over $80 \%$ of respondents reported their first dose of fingolimod was moderately, very, or extremely manageable, convenient, and easy to take. Approximately $80 \%$ of patients reported experiencing a side effect during the first dose. Among patients experiencing a side effect $(n=304)$, many $(42.4 \%)$ reported the side effect was "not at all" or only "a little" difficult to tolerate. Overall, patients with no side effects reported higher levels of satisfaction with the first-dose experience than patients experiencing side effects (data not shown). Figure 3 reports the results of the first-dose experience questions (see Table S1). Only eleven respondents $(2.9 \%)$ reported a "not at all satisfied" first-dose experience.

\section{TSQM results}

Overall, current users of fingolimod were satisfied with the treatment. The highest TSQM domain score was reported for side effects (79.4), followed by convenience (71.7), effectiveness (70.1), and global satisfaction (68.9).

When stratified by prior treatment experience, no significant differences are observed between groups in the TSQM side effect domain $(P=0.1148)$. However, significantly higher scores were reported among treatment-experienced users $(n=223)$ than treatment-naïve users $(n=87)$ in all other domains: effectiveness (72.7 versus $63.3 ; P=0.0002$ ), convenience (75.5 versus $62.0 ; P<0.0001$ ), and global satisfaction (71.5 versus 62.2; $P=0.0007$ ) (Figure 4).

Among respondents who were treated with at least one other DMT $(n=273), 58 \%$ reported their first choice for MS treatment would be fingolimod if selecting today. Glatiramer acetate ranked second with $13 \%$ of respondents.

\section{Discussion}

To the authors' best knowledge, the present survey study is the first to report real-world FDO and treatment experience with fingolimod from a patient perspective. Although some may consider the recommended 6-hour FDO period a deterrent to initiating fingolimod treatment for patients with MS, fewer than 3\% of patients who had taken at least one dose of fingolimod reported being unsatisfied with the FDO experience.

The finding that $80 \%$ of patients reported experiencing a side effect with the first dose of fingolimod needs further consideration, as it should be noted that rather than asking "did you experience side effects with your first dose of fingolimod?" (yes/no), this result was derived from a complex question that asked patients "overall, how difficult was it to tolerate any side effects experienced during your first dose of Gilenya [fingolimod]?" Most questions related to the first-dose experience were phrased so that there were five response options, ranging from "not at all" to "extremely" (see Table S1). This question was similarly phrased; however, there was an additional response option of "I did not experience any side effects at all," by which patients could deny experiencing a side effect. Only patients who selected this option were considered to not have 
Table I Sociodemographic and clinical characteristics

\begin{tabular}{|c|c|c|}
\hline \multirow[t]{2}{*}{ Characteristic } & \multicolumn{2}{|l|}{ n (\%) or mean (SD) } \\
\hline & Current fingolimod users $(n=310)$ & All respondents $(n=380)$ \\
\hline Age (in years) & $38.8(11.8)$ & $39.8(12.6)$ \\
\hline Female gender & $163(52.6 \%)$ & $211(55.5 \%)$ \\
\hline \multicolumn{3}{|l|}{ Ethnicity } \\
\hline Hispanic or Latino & $4 \mathrm{I}(13.2 \%)$ & $48(12.6 \%)$ \\
\hline \multicolumn{3}{|l|}{ Race } \\
\hline White & $245(79.0 \%)$ & $305(80.3 \%)$ \\
\hline Black or African American & $40(12.9 \%)$ & $46(12.1 \%)$ \\
\hline Asian & 24 (7.7\%) & $28(7.4 \%)$ \\
\hline Native Hawaiian or Pacific Islander & $3(1.0 \%)$ & $4(1.1 \%)$ \\
\hline American Indian or Alaska Native & I (0.3\%) & $3(0.8 \%)$ \\
\hline Other & $5(1.6 \%)$ & $8(2.1 \%)$ \\
\hline \multicolumn{3}{|l|}{ Employment status } \\
\hline Employed, full-time & I 47 (47.4\%) & $164(43.2 \%)$ \\
\hline Employed, part-time & $42(13.6 \%)$ & $48(12.6 \%)$ \\
\hline Homemaker & $17(5.5 \%)$ & $23(6.1 \%)$ \\
\hline Student & $13(4.2 \%)$ & $17(4.5 \%)$ \\
\hline Unemployed & $18(5.8 \%)$ & $19(5.0 \%)$ \\
\hline Retired & II (3.6\%) & $17(4.5 \%)$ \\
\hline Disabled & 61 (19.7\%) & 91 (23.9\%) \\
\hline Other & I (0.3\%) & I (0.3\%) \\
\hline \multicolumn{3}{|l|}{ Type of MS diagnosed } \\
\hline Relapsing remitting MS & $157(50.6 \%)$ & $198(52.1 \%)$ \\
\hline Clinically isolated syndrome & $65(21.0 \%)$ & $70(18.4 \%)$ \\
\hline Secondary progressive MS & $56(18.1 \%)$ & $7 \mathrm{l}(18.7 \%)$ \\
\hline Progressive MS without relapses & $23(7.4 \%)$ & $26(6.8 \%)$ \\
\hline Unknown & $9(2.9 \%)$ & $15(3.9 \%)$ \\
\hline \multicolumn{3}{|c|}{ Prior DMT experience (last DMT before fingolimod) } \\
\hline None & $87(28.1 \%)$ & $107(28.2 \%)$ \\
\hline Interferon beta-Ia (Avonex) & $33(10.6 \%)$ & $34(8.9 \%)$ \\
\hline Interferon beta-Ia (Rebif) & $27(8.7 \%)$ & 35 (9.2\%) \\
\hline Interferon beta-Ib (Betaseron or Extavia) & $60(19.4 \%)$ & $74(19.5 \%)$ \\
\hline Glatiramer acetate (Copaxone) & $63(20.3 \%)$ & $73(19.2 \%)$ \\
\hline Natalizumab (Tysabri) & $24(7.7 \%)$ & $32(8.4 \%)$ \\
\hline Other & $16(5.9 \%)$ & $25(6.6 \%)$ \\
\hline Time since first MS symptom (in years) ${ }^{\mathrm{a}}$ & $11.4(11.1)$ & $12.0(11.3)$ \\
\hline Time since MS diagnosis (in years) ${ }^{\mathrm{b}}$ & $9.4(10.3)$ & $9.8(10.3)$ \\
\hline \multicolumn{3}{|l|}{ Number of lifetime MS relapses, $n$ (\%) } \\
\hline $0-1$ & $23(7.4 \%)$ & $29(7.6 \%)$ \\
\hline $2-3$ & $10 \mathrm{I}(32.6 \%)$ & $116(30.5 \%)$ \\
\hline $4-6$ & $83(26.8 \%)$ & $96(25.3 \%)$ \\
\hline $7-9$ & 40 (12.9\%) & $49(12.9 \%)$ \\
\hline $10+$ & $63(20.3 \%)$ & $90(23.7 \%)$ \\
\hline Number of MS relapses in past 6 months & $\mathrm{I} .5(\mathrm{I} .6)$ & $\mathrm{I} .5(\mathrm{I} .8)$ \\
\hline Time since last MS relapse (in years) $^{c}$ & $3.5(7.5)$ & $3.3(7.1)$ \\
\hline \multicolumn{3}{|l|}{ Patient determined disease steps, $\mathrm{n}(\%)$} \\
\hline Normal (0) & $76(24.5 \%)$ & $85(22.4 \%)$ \\
\hline Mild disability (I) & $69(22.3 \%)$ & $8 \mathrm{I}(2 \mathrm{I} .3 \%)$ \\
\hline Moderate disability (2) & $55(17.7 \%)$ & $64(16.8 \%)$ \\
\hline Gait disability (3) & $48(15.5 \%)$ & $59(15.5 \%)$ \\
\hline Early cane (4) & $28(9.0 \%)$ & $4 \mathrm{I}(10.8 \%)$ \\
\hline Late cane (5) & $23(7.4 \%)$ & $32(8.4 \%)$ \\
\hline Bilateral support $(6)$ & $4(1.3 \%)$ & $8(2.1 \%)$ \\
\hline Wheelchair/scooter (7) & $4(1.3 \%)$ & $7(1.8 \%)$ \\
\hline Bedridden (8) & $3(1.0 \%)$ & $3(0.8 \%)$ \\
\hline
\end{tabular}

Notes: ${ }^{\mathrm{T} T i m e}$ since first MS symptom calculated as (date of survey completion) - (date of first MS symptoms); bime since MS diagnosis calculated as (date of survey completion) - (date of MS diagnosis). 'Time since last MS relapse calculated as (date of survey completion) - (date of last MS relapse).

Abbreviations: n, number; SD, standard deviation; MS, multiple sclerosis; DMT, disease-modifying therapy. 
Table 2 Reasons for starting or switching to fingolimod

\begin{tabular}{|c|c|c|}
\hline \multirow[t]{2}{*}{ Primary reasons ${ }^{a}$} & \multicolumn{2}{|l|}{ n (\%), responses } \\
\hline & $\begin{array}{l}\text { Treatment- } \\
\text { experienced } \\
\text { patients switching } \\
\text { to fingolimod }\end{array}$ & $\begin{array}{l}\text { Treatment- } \\
\text { naïve patients } \\
\text { starting } \\
\text { fingolimod }\end{array}$ \\
\hline $\begin{array}{l}\text { Physician } \\
\text { recommendation }\end{array}$ & $148(15.6 \%)$ & 68 (32.7\%) \\
\hline $\begin{array}{l}\text { Convenience of oral } \\
\text { medication }\end{array}$ & 146 (15.4\%) & 24 (II.5\%) \\
\hline $\begin{array}{l}\text { Side effects with } \\
\text { previous treatment }\end{array}$ & 118 (12.5\%) & $\mathrm{N} / \mathrm{A}$ \\
\hline $\begin{array}{l}\text { Treatment failure } \\
\text { with prior medication }\end{array}$ & $104(11.0 \%)$ & $N / A$ \\
\hline $\begin{array}{l}\text { Dislike of injections/ } \\
\text { infusions }\end{array}$ & $103(10.9 \%)$ & $20(9.6 \%)$ \\
\hline $\begin{array}{l}\text { Expect few(er) or } \\
\text { tolerable side effects }\end{array}$ & 95 (10.0\%) & $28(13.5 \%)$ \\
\hline $\begin{array}{l}\text { Expected efficacy } \\
\text { of fingolimod }\end{array}$ & 95 (10.0\%) & 27 (I3.0\%) \\
\hline $\begin{array}{l}\text { Ability to take } \\
\text { medication at home }\end{array}$ & 71 (7.5\%) & $28(\mid 3.5 \%)$ \\
\hline $\begin{array}{l}\text { Expected safety } \\
\text { of fingolimod }\end{array}$ & 40 (4.2\%) & 10 (4.8\%) \\
\hline Cost & $18(1.9 \%)$ & $2(1.0 \%)$ \\
\hline
\end{tabular}

Note: aparticipants asked to report all primary reasons for starting/switching; percentages represent proportion of total responses $(n=947$ in treatmentexperienced patients; $\mathrm{n}=208$ in treatment-naïve patients).

Abbreviations: $\mathrm{n}$, number; N/A, not applicable.

experienced a side effect. While this may be an accurate finding, the authors feel that the complexity of the question may have lead to an over-reporting of side effects for fingolimod, particularly given the contrasting results for satisfaction with the first-dose experience.

Despite the approval of fingolimod as a first-line MS treatment, nearly three-quarters of patients surveyed had switched from a prior DMT, perhaps due to fingolimod's novel mechanism of action or its recent FDA approval. Similar to findings of another study, ${ }^{3}$ side effects and a lack of treatment efficacy were reported among the top reasons for switching to fingolimod from other DMT therapies.

Significant differences in sociodemographic and clinical characteristics between treatment-naïve and treatmentexperienced current fingolimod users were observed in this study. These findings are expected given the epidemiology of MS and recent market availability of fingolimod. Patients who are treatment-naïve are more likely to be newly diagnosed with MS and/or have less MS-related disability given they did not previously require or receive treatment. On the other hand, the mean number of MS relapses during the previous 6 months was remarkably similar between treatment-naïve and treatment-experienced users ( 1.4 versus 1.5 , respectively; $P=0.5337$ ). While the design of the current study limits our ability to draw conclusions about the relative efficacy of fingolimod versus other DMTs, we do know from this study that approximately $11 \%$ of patients switched from their prior DMT to fingolimod due to treatment failure.

Differences observed in TSQM scale scores reported by treatment-naïve and treatment-experienced fingolimod users were also notable and likely reflect different expectations in these two populations. Patients with prior DMT experience reported higher scores for the convenience, efficacy, and global satisfaction domains than patients with no prior DMT use, suggesting fingolimod is perceived to be more desirable than other DMTs in these domains among patients who have previous experience with other DMTs. A comparative study with other DMTs would more robustly address this question.

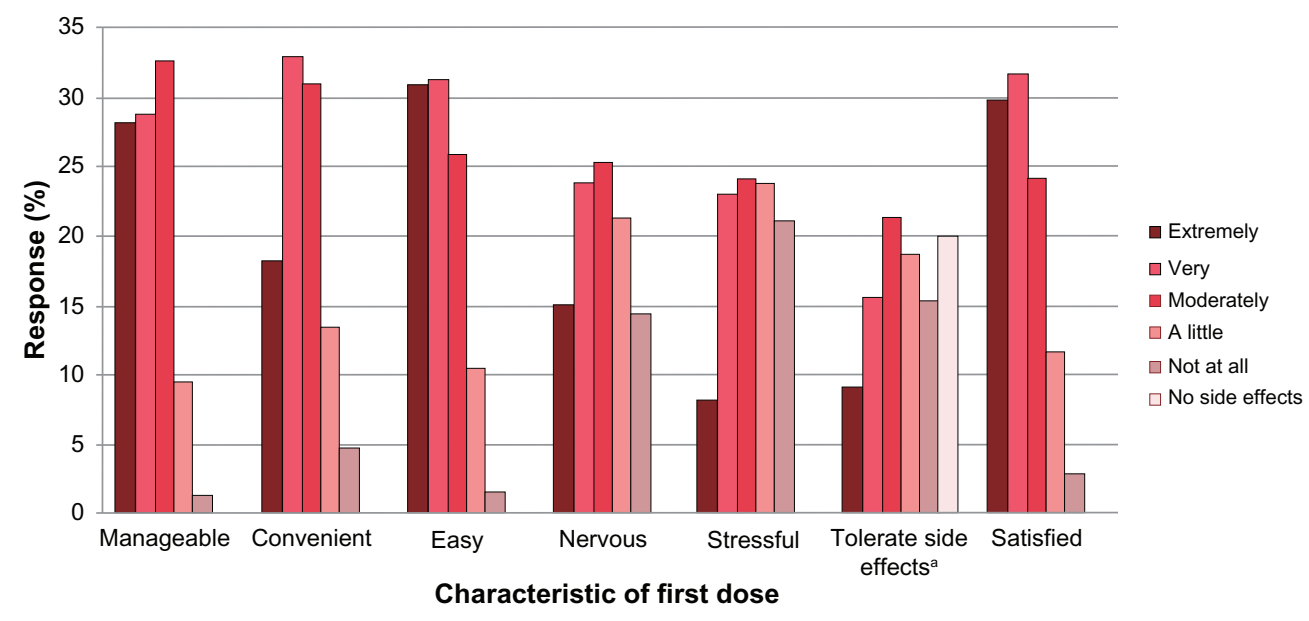

Figure 3 First dose experience.

Note: aQuestion refers to difficulty tolerating side effects (“'Overall, how difficult was it to tolerate any side effects experienced during your first dose of Gilenya [fingolimod]?"). 


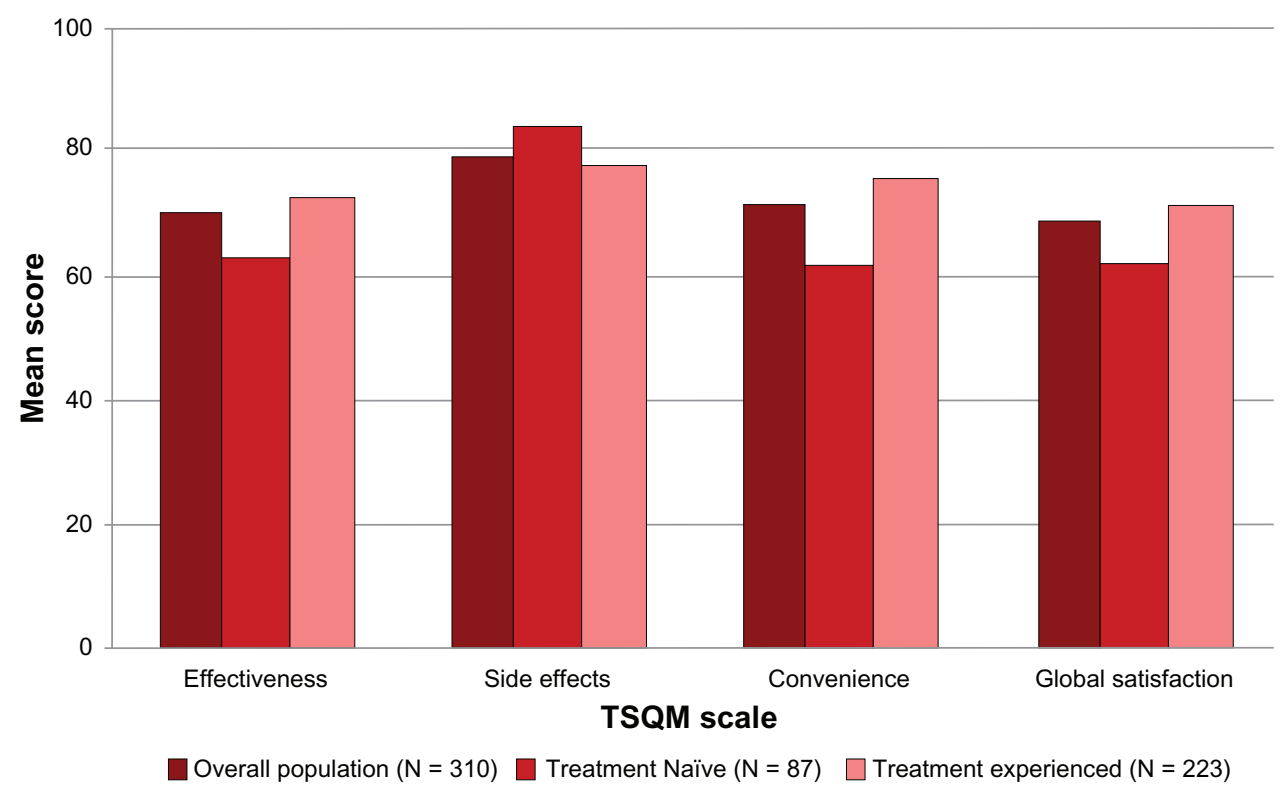

Figure 4 TSQM scale scores, overall and by treatment experience.

Abbreviations: TSQM, Treatment Satisfaction Questionnaire for Medication; n, number.

The present study was designed to collect real-world fingolimod treatment satisfaction data from patients. However, there are several limitations to this study that should be noted. First of all, all measures in this survey were self-reported, including the diagnosis of MS. Also, since this was a crosssectional, web-based survey study, an objective assessment of clinical characteristics and change over time was not possible. The authors acknowledge that use of a web-based survey may limit the generalizability of the study, as patients who do not have access to the Internet, or who may be less comfortable with this technology (eg, elderly patients) are likely to be underrepresented. Nonetheless, when it comes to the collection of patient perspective data, a web-based market research panel remains a cost-effective method compared to the on-site patient survey administration, as it enables researchers to quickly reach out to a large number of potential respondents to achieve the target sample size; moreover, data collection is completed in a timely manner, and database management is simplified.

As mentioned previously, the date of fingolimod initiation was purposely not included as part of the study inclusion/ exclusion criteria. This was done both in order to achieve an adequate sample size and to allow for examination of the treatment satisfaction over time. However, it is possible that the length of time that passed between the first fingolimod dose and survey completion could lead to recall bias with regards to the FDO experience; however, given the relatively recent FDA approval of fingolimod, the maximum amount of time between first dose and survey completion was 21.6 months and approximately half of respondents (53.4\%) started fingolimod within the prior year.

Finally, some study limitations exist due to the limited content of the survey. For example, respondents were not asked to evaluate their satisfaction with other DMTs, thus no direct comparison could be made between fingolimod and other medications. Secondly, costs of medications were not assessed in this study. Hence, it is unclear if cost of medications had an impact on satisfaction for patients.

\section{Conclusion}

This survey demonstrated that more than $97 \%$ of patients were satisfied with the overall fingolimod first-dose experience. Moreover, treatment satisfaction with fingolimod was specifically higher among treatment-experienced patients compared to treatment-naïve patients. Among patients with prior DMT experience, over half stated that their first choice for MS treatment would be fingolimod if selecting today, compared to $13 \%$ for the second highest DMT, glatiramer acetate.

Additional research is needed to understand key clinical and medication attributes underlying treatment satisfaction with fingolimod and other DMTs, as well as to compare treatment satisfaction among different DMTs. Specifically, longitudinal comparative studies are needed to confirm current findings, measure long-term satisfaction, and assess patient preference across a range of treatment options. 


\section{Disclosure}

This study was funded by Novartis Pharmaceuticals Corporation, East Hanover, NJ. KAH, SMS, and ZB are employees of United BioSource Corporation, which received funding for this research from Novartis. NA is an employee of Novartis. DWB serves on advisory panels for the following companies: Biogen Idec, Teva, Novartis, Genzyme, Sanofi, Acorda; serves on speaking panels for the following: Biogen Idec, Teva, Novartis, Genzyme, Acorda, Questcor, Avanir; and receives research support from Biogen Idec and Teva.

\section{References}

1. Girouard N, Soucy N. Patient considerations in the management of multiple sclerosis: development and clinical utility of oral agents. Patient Prefer Adherence. 2011;5:101-108.

2. National Multiple Sclerosis Society. Fact sheet: multiple sclerosis [webpage on the Internet]. New York, NY: National Multiple Sclerosis Society; 2012. Available from: http://www.nationalmssociety.org/chapters/mnm/ mediacenter/factsheetmultiplesclerosis/index.aspx. Accessed October 18, 2012.

3. Giovannoni G, Southam E, Waubant E. Systematic review of diseasemodifying therapies to assess unmet needs in multiple sclerosis: tolerability and adherence. Mult Scler. 2012;18(7):932-946.

4. Kappos L, Radue EW, O'Connor P, et al; for FREEDOMS Study Group. A placebo-controlled trial of oral fingolimod in relapsing multiple sclerosis. N Engl J Med. 2010;362(5):387-401.

5. Cohen JA, Barkhof F, Comi G, et al; for TRANSFORMS Study Group. Oral fingolimod or intramuscular interferon for relapsing multiple sclerosis. N Engl J Med. 2010;362(5):402-415.

6. Roskell NS, Zimovetz EA, Rycroft CE, Eckert BJ, Tyas DA. Annualized relapse rate of first-line treatments for multiple sclerosis: a meta-analysis, including indirect comparisons versus fingolimod. Curr Med Res Opin. 2012;28(5):767-780.

7. Agashivala N, Wu N, Abouzaid S, et al. Comparison of compliance with fingolimod and other first-line disease-modifying treatments among patients with multiple sclerosis. Proceedings of the Academy of Managed Care Pharmacy (AMCP) Education Conference; October 3-5, 2012; Cincinnati, OH, USA.
8. Agashivala N, Wu N, Wu Y, Kim E, Boulanger L, Brandes D Comparison of time to discontinuation among multiple sclerosis patients receiving fingolimod and other first-line disease-modifying treatments. Proceedings of the European Committee for Research and Treatment in Multiple Sclerosis (ECTRIMS) Congress; October 10-13, 2012; Lyon, France.

9. O’Rourke KE, Hutchinson M. Stopping beta-interferon therapy in multiple sclerosis: an analysis of stopping patterns. Mult Scler. 2005;11(1):46-50.

10. Tremlett HL, Oger J. Interrupted therapy: stopping and switching of the beta-interferons prescribed for MS. Neurology. 2003;61:551-554.

11. Gilenya ${ }^{\circledR}$ (fingolimod) [package insert]. East Hanover, NJ: Novartis Pharmaceuticals Corporation; 2010.

12. DiMarco JP, O'Connor P, Cohen JA, et al. Fingolimod treatment initiation experience: cardiac and Holter electrocardiogram findings from three phase 3 studies. Proceedings of the European Committee for Research and Treatment in Multiple Sclerosis (ECTRIMS) Congress; October 10-13, 2012; Lyon, France.

13. Kurtzke JF. Rating neurologic impairment in multiple sclerosis: an expanded disability status scale (EDSS). Neurology. 1983;33(11): 1444-1452.

14. Motl RW, Fernhall B, McAuley E, Cutter G. Physical activity and self-reported cardiovascular comorbidities in persons with multiple sclerosis: evidence from a cross-sectional analysis. Neuroepidemiology. 2011;36(3):183-191.

15. Hohol MJ, Orav EJ, Weiner HL. Disease steps in multiple sclerosis: a simple approach to evaluate disease progression. Neurology. 1995; 45(2):251-255

16. Kobelt G, Berg J, Atherley D, Hadjimichael O. Cost and quality of life in multiple sclerosis: a cross-sectional study in the United States. Neurology. 2006;66(11):1696-1702.

17. Schwartz CE, Vollmer T, Lee H. Reliability and validity of two selfreport measures of impairment and disability for MS. North American Research Consortium on Multiple Sclerosis Outcomes Study Group. Neurology. 1999;52(1):63-70.

18. Atkinson MJ, Sinha A, Hass SL, et al. Validation of a general measure of treatment satisfaction, the Treatment Satisfaction Questionnaire for Medication (TSQM), using a national panel study of chronic disease. Health Qual Life Outcomes. 2004;2:12. 


\section{Supplementary table}

Table SI Survey questions about first-dose experience

I. Thinking about your first-dose experience overall, including the time you spent at your doctor's office when you received your first dose of Gilenya [fingolimod], how manageable was your first-dose experience?
$\square$ Not at all
$\square$ A little
$\square$ Moderately
$\square$ Very
$\square$ Extremely

2. Thinking about your first-dose experience overall, including the time you spent at your doctor's office when you received your first dose of Gilenya [fingolimod], how convenient was your first-dose experience?

$\square$ Not at all

$\square$ A little

$\square$ Moderately

$\square$ Very

$\square$ Extremely

3. Overall, how easy was it to take your first dose of Gilenya [fingolimod]?
$\square$ Not at all
$\square$ A little
$\square$ Moderately
$\square$ Very
$\square$ Extremely

4. Thinking about how you felt prior to going to your doctor's office for your first dose, overall, how nervous were you about your first-dose experience?

$\square$ Not at all

$\square$ A little

$\square$ Moderately

$\square$ Very

$\square$ Extremely

5. Thinking about your experiences during your first-dose observation period at your doctor's office, overall, how stressful was your first-dose experience? $\square$ Not at all

$\square$ A little

$\square$ Moderately

$\square$ Very

$\square$ Extremely

6. Overall, how difficult was it to tolerate any side effects experienced during your first-dose of Gilenya [fingolimod]?

$\square$ Not at all

$\square$ A little

$\square$ Moderately

$\square$ Very

$\square$ Extremely

$\square$ I did not experience any side effects

7. Overall, how satisfied were you with your first-dose experience?

$\square$ Not at all

$\square$ A little

$\square$ Moderately

$\square$ Very

$\square$ Extremely

Patient Preference and Adherence

\section{Dovepress}

\section{Publish your work in this journal}

Patient Preference and Adherence is an international, peer-reviewed, open access journal focusing on the growing importance of patient preference and adherence throughout the therapeutic continuum. Patient satisfaction, acceptability, quality of life, compliance, persistence and their role in developing new therapeutic modalities and compounds to

optimize clinical outcomes for existing disease states are major areas of interest. This journal has been accepted for indexing on PubMed Central. The manuscript management system is completely online and includes a very quick and fair peer-review system. Visit http://www.dovepress.com/ testimonials.php to read real quotes from published authors. 